Fecha de recepción: diciembre 2012 Fecha de aceptación: septiembre 2013 Versión final: septiembre 2014

\section{La imagen emotiva como lenguaje de la creatividad e innovación}

Deyanira Bedolla Pereda ${ }^{\star} y$

Aarón José Caballero Quiroz ${ }^{\star *}$

\begin{abstract}
Resumen: Una manera de abordar la enseñanza del diseño desde la creatividad y su consecuencia, la innovación, es propiciando en los alumnos la vivencia de experiencias sensoriales y emotivas. La detección y caracterización de problemáticas a resolver por medio del diseño, desde la perspectiva de este tipo de experiencias, conduce a los alumnos a construir "imágenes" más precisas para dar respuestas afectivo-significativas durante el proceso de diseño.
\end{abstract}

Palabras clave: creatividad - diseño - emociones - experiencias - imágenes - innovación.

[Resúmenes en inglés y portugués en la página 89]

${ }^{*}$ Doctora en Proyectos de Innovación Tecnológica 2002 (UPC- Barcelona España). Maestra en Diseño y Biónica 1998 (IED-Milán Italia) y Licenciada en Diseño Industrial 1995 (UAM México). Profesora Investigadora en la Universidad Autónoma Metropolitana unidad Cuajimalpa (UAM - Cuajimalpa). Coordinadora del Cuerpo Académico Evaluación del Diseño Centrada en el Usuario que busca conocer y estudiar la cualidad y calidad de la interacción del ser humano con el diseño.

${ }^{(*)}$ Doctor en Teoría e Historia de la Arquitectura 2008 (UPC, España) y Licenciado en Arquitectura (UNAM). Profesor Investigador en la Universidad Autónoma Metropolitana, Unidad Cuajimalpa (UAM-Cuajimalpa). Miembro del Cuerpo Académico Evaluación del Diseño Centrada en el Usuario en donde revisa la conformación del sujeto desde la mirada moderna que éste manifiesta, a través de textos y reflexiones relativas a la filosofía.

\title{
Introducción
}

El presente trabajo responde a dos aspectos fundamentales, el primero de ellos se refiere a que el proceso de enseñanza aprendizaje en el área de diseño siempre ha planteado el reto de fomentar en el alumno la creatividad e innovación para la proyección del diseño, ya que se trata de dos aspectos fundamentales para el área, sin embargo no son dos tareas sencillas de propiciar y de guiar ya que se trata de quehaceres complejos y multifactoriales, por ello es siempre necesario y deseable, en el ámbito docente, seguir pensando los caminos que conduzcan al alumno para llegar a ellos con el fin de optimizar los existentes y 
proponer nuevas vías, estrategias y herramientas que le permitan ser creativo e innovador. El segundo aspecto al que responde este trabajo es la consideración que el estudiante debiera tener sobre la dimensión afectiva emocional del diseño cuya importancia central ha sido recientemente reconocida para cualquier elemento del mundo artificial que se conciba, sea del ámbito comunicativo, sea un objeto, espacio e inclusive un servicio. Esto ocasiona que para el docente en la actualidad sea una asignatura pendiente el identificar dentro de los procesos de enseñanza aprendizaje del diseño, las herramientas y estrategias que le permitan al estudiante conocer e integrar, mediante el lenguaje del diseño, esta dimensión humana tan relevante.

El objetivo de este trabajo es exponer, la experiencia obtenida de llevar a las aulas un concepto de enseñanza basado en la experiencia emotiva, en donde la intención fue lograr un aprendizaje que estimulara la creatividad del alumno y principalmente le permitiera desarrollar la capacidad de proyectar la complejidad afectiva emocional a través de entender el impacto que tienen las emociones en el individuo, aspecto que lo condujo a vivir aquellas experiencias emotivas en tanto que medio para la comprensión y estudio de la emociones humanas así como su proyección a través del lenguaje del diseño.

Conducir al alumno a la detección y caracterización de problemáticas a resolver por medio del diseño, desde la perspectiva de experiencias emotivas, permitió a los alumnos a construir "imágenes" más precisas que dieran respuestas afectivo-significativas durante el proceso de diseño.

\section{La otra dimensión del Diseño}

Tradicionalmente la enseñanza del diseño centraba sus esfuerzos principalmente en el conocimiento, desarrollo y satisfacción de la dimensión funcional del diseño, lo que implicaba identificar y estudiar necesidades prácticas así como conocer principalmente características físicas de los usuarios a los cuales se dirigen los productos del diseño. Sin embargo, la identificación y estudio de dimensiones humanas relacionadas con la dimensión afectiva emocional del diseño evidenciaron la importancia que tiene esta última tanto como la dimensión funcional, en la aceptación de dichos productos, tal y como ya se ha señalado en trabajos anteriores (Bedolla, 2009).

Lo anterior no significa que desde la creación de las primeras escuelas de diseño no se hubiera considerado de alguna manera la dimensión afectiva emocional, es solo que, y debido a la apremiante urgencia de reconstruir las distintas naciones de Europa tras su devastación por la Segunda Guerra Mundial, los procesos de producción y su estandarización cobraron una mayor importancia dejando pendiente, y en ocasiones en el olvido, la dimensión de la que es objeto este trabajo. A ello habría que agregar la enorme brecha de significado que hay entre el enfoque que se hacía de la dimensión afectiva emocional o su equivalente, dentro de escuelas de diseño como la Bauhaus, en donde ni siquiera éste era el término empleado para denominarla por sus profesores y alumnos, debido en gran medida a que dicha dimensión es no solo un término acuñado recientemente, consecuencia de estudios hechos por disciplinas como la psicología, sino que además lo emocional o su 
equivalente era planteado como parte de una autorrealización, propia de los artistas, que poco o nada tiene que ver con el enfoque que se abordará mas adelante.

El interés en esta otra dimensión humana ha llegado a ser un hot topic (Desmet, 1998) para los profesionales del campo del diseño por un lado, y por otro, ha permitido un renacimiento del mismo, un renovado interés que se ha reflejado en la búsqueda de productos de diseño en el mercado por el usuario (Gobé, 2005); en la actualidad se reconoce que el éxito de un objeto en el mercado puede ser determinado en gran medida por su apariencia estética y por el placer y la satisfacción que produce en el usuario (Khalid and Helander, 2004, Helander and Khalid, 2006).

Por todo lo anterior como el ámbito de la docencia no puede estar al margen de ello es necesario integrar la dimensión afectiva emocional como temática de estudio y por supuesto de proyección del diseño, dado que actualmente no es un contenido que sea explícito en los programas de estudio en la UAM Cuajimalpa, al igual que sus estrategias de enseñanza aprendizaje.

Uno de las perspectivas para abordar el estudio de esta dimensión es la multisensorial humana ya que desde el ámbito de la investigación académica ha representado un enfoque esencial para el conocimiento del usuario y al mismo tiempo de los elementos que integran el lenguaje del diseño que van a permitir satisfacer sus necesidades e inclinaciones derivadas directa e indirectamente de los procesos sensoriales humanos (Bedolla, 2012); dicha utilidad es posible extenderla al ámbito docente donde la dimensión multisensorial del estudiante, representa una herramienta cognitiva de la que el docente puede echar mano para conducir al alumno a conocer, propiciando en él una participación activa en su propio proceso de enseñanza aprendizaje al conducirle a abordar de una manera muy natural y sobre todo activa la identificación, entendimiento y estudio de la dimensión afectiva humana en relación a la proyección del diseño.

Este modo de conocimiento es congruente con las características del modo constructivista de enseñanza aprendizaje ya que se trata de la propuesta de un proceso dinámico y participativo del estudiante, de modo que se le conduce a que su conocimiento sea en gran medida una construcción operada por el estudiante mismo.

La amplia utilidad de la perspectiva sensorial humana se explica, ya que es el conjunto de los sentidos la vía perceptiva de la información del entorno y estos mismos tienen un papel vital en el gusto o rechazo del elemento de diseño (espacio, objeto o información digital). Ya desde el nivel básico perceptivo un objeto o un espacio nos gustará o disgustará a través de la apreciación de la sensación en sí, de su cualidad e intensidad. En un nivel secundario continúa este proceso de evaluación del elemento a través de procesos más complejos -emociones, sentimientos y deseos- procesos que consisten en excitación sensorial y valoración cognitiva a través de impresiones y recuerdos (Bedolla, 2012).

La multisensorialidad es una de las características del individuo más trascendentes, que no solo abarca en toda persona lógicamente dimensiones orgánicas y físicas, sino que paralelamente abarca dimensiones emocionales. Dicha naturaleza de la percepción multisensorial permite que como perspectiva en el estudio del usuario sea de gran utilidad ya que define necesidades humanas de ámbito tanto físico como anímico, a las que es posible satisfacer a través de los elementos que integran nuestro entorno artificial de muy diversas 
maneras. Al mismo tiempo, como parte de la naturaleza perceptiva humana, conduce a todo individuo a la realización de juicios o evaluaciones integrales de todo lo que sucede e integra su entorno tanto de forma lógico racional como intuitiva irracional.

\section{La dimensión emocional y las experiencias emotivas del diseño}

La satisfacción del ámbito afectivo emocional a través del diseño tiene gran trascendencia por que se trata de otro tipo de necesidades directamente relacionadas con el bienestar general del individuo. Se trata de la satisfacción de dimensiones y constantes intrínsecamente humanas a través de productos, informaciones o espacios de manera que es posible maximizar su placer de uso y con ello la calidad de vida de las personas.

En la actualidad existe evidencia de que objetos estéticamente placenteros permiten trabajar mejor; se ha demostrado que los productos y sistemas que hacen sentir bien conducen más fácilmente a tener armoniosos resultados.

Como ya se ha mencionado en anteriores trabajos, las emociones para todo individuo son fundamentales, una parte necesaria e inseparable de la cognición que influye en la percepción y en tareas cotidianas como el aprendizaje, la comunicación y aún en la toma de decisiones racionales, por lo cual todo lo que hacemos y todo lo que pensamos está matizado por las emociones y mucho de ello inclusive a nivel subconsciente. Por lo tanto nuestras emociones cambian la manera en que pensamos y nos sirven como guías constantes para comportamientos apropiados (Norman, 2004).

La importancia de las emociones radica también en que permiten llevar a cabo juicios rápidos y pasajeros. Se nos presentan como la información más inmediata acerca del mundo: aquí hay un peligro potencial, confort o comodidad potencial, esto es bonito, esto feo. Un modo por el cual las emociones trabajan es a través de transmisores neuro químicos que bañan particulares centros del cerebro modificando la percepción, la toma de decisiones, y el comportamiento, esos neuroquímicos cambian los parámetros del pensamiento. Uno de las maneras de abordar y entender más claramente en el diseño la dimensión afectiva emocional humana, ha sido el enfoque de los productos del diseño como experiencias de vida, experiencias que están integradas por supuesto por dimensiones tan distintas hasta las hoy estudiadas, y por lo tanto inexploradas como lo es la afectiva - emocional. De este modo hoy es claro que el diseño no es únicamente un medio que permite cumplir un sin número de fines prácticos como el transportarnos o comunicarnos por ejemplo, sino que es mucho mas que eso: es un medio que tiene la capacidad de hacer significativa la vida cotidiana de la gente; D. Norman (en Cañada 2005) lo señala claramente: "El diseño está relacionado con las emociones de muchas formas distintas: a veces nos divertimos usando ciertos objetos, otras nos enfadamos cuando nos cuesta usarlos. Disfrutamos contemplando algunas cosas y nos encanta lucir otras porque nos hacen sentir distintos. Hay objetos que nos traen recuerdos, por como huelen, por su tacto, y otros que no queremos tirar a la basura y nos gusta cómo envejecen".

Muchas experiencias cotidianas en que simplemente se usan y disfrutan los productos, son centrales para la vida de las personas: la sensación confortable de un desarmador en la mano, el amigable silbido de una tetera, la frustración provocada por la baja calidad de 
un sistema de ayuda on line, el delicioso aroma de una tarta de manzana recién horneada, o el alivio de estacionar suavemente el auto en un espacio estrecho, construyen o podrían construir nuestra vida diariamente.

Para la creación de experiencias, el diseñador necesita tener claro cómo le es posible crear elementos y contextos en los cuales las personas puedan disfrutar una película, la cena, hacer la limpieza, jugar, trabajar, con todos sus sentidos.

Por lo cual hoy en día la tarea del diseñador es hacer que la función de los productos espacios, y comunicaciones sean accesible al individuo mientras, al mismo tiempo, le permiten una interacción con el elemento de diseño en una forma placentera, divertida, agradable, etc., ya que no se trata de solamente evitar que se frustre el usuario durante el uso, sino que productos, espacios y comunicaciones, pudieran ser sorpresivos, seductores, elegantes, finos, gratificantes, atractivos, temperamentales e inclusive excitantes.

De esta manera abordar la dimensión afectiva emocional humana y satisfacerla a través del diseño aporta la posibilidad de aumentar la calidad de vida de los usuarios a través de comunicaciones, objetos, espacios y servicios que permitan a las personas vivir cotidianamente experiencias significativas de vida. Al mismo tiempo en el ámbito docente las experiencias además pueden representar una herramienta cognitiva que permita estimular la creatividad y propiciar la innovación del futuro diseñador; esto significaría para el estudiante diseñar emociones viviéndolas.

Con base en lo anterior nos plantemos principalmente las preguntas siguientes: ¿Cómo lograr conducir al estudiante de diseño a conocer y entender, la dimensión afectiva emocional del diseño desde sus elementos más básicos es decir las emociones? ¿Cómo conducirlo a conocer la naturaleza y expresión emotiva humana en relación a los productos de diseño? ¿De qué manera conducirlo a expresar y traducir emociones mediante el lenguaje de diseño?

\section{Introducir al alumno al tema diseño y emociones}

El tema de conocer y conducir al individuo a la experimentación de emociones a través del diseño, es un tema actual y muy relevante de nuestra disciplina hoy en día, sin embargo es igualmente un tema complejo y la discusión de cómo aplicarlo en el diseño tanto de elementos digitales como de otro tipo de productos no es la excepción. Desmet y Hekkert (2009) igualmente señalan que si bien la temática de diseño y emociones dio inicio alrededor de 1999 y a partir de entonces ha sido un campo de estudio ampliamente explorado, aún existe sin embargo mucho que hacer, muchas preguntas que plantear y mucho que explorar en general, incluyendo por supuesto al ámbito docente.

De este modo hasta ahora poco se ha escrito acerca de cómo enseñar esta materia. Existen escasos ejemplos de ello entre los que se pueden referir esfuerzos realizados para tratar de abordar la enseñanza desde una dimensión afectiva emocional, entre ellos se encuentra la labor que la Dra. Alba (2010) hace en la Universidad de Sevilla con alumnos de la carrera de Arquitectura. Las Intersecciones a las que propone llegar la autora son el resultado del acto azaroso de entretejer caminos que parten de recuerdos, evocaciones, aspiraciones y preferencias del alumno con informaciones cuantitativas muy concretas, específicas y fun- 
cionales sobre los requerimientos propios del proyecto a tratar, teniendo como principal consigna rescatar y acaso de alguna manera traer a la presencia afectos y emociones que ennoblecen una propuesta de diseño.

Un ejemplo más es el de Denton (2004) de la Universidad de Loughborough en Inglaterra, que para introducir a los estudiantes a entender el rol de las emociones en el diseño los conducen a realizar tres ejercicios; justamente uno de ellos se trata de un ejercicio imaginativo fuera del ambiente escolar. En él se les plantea un contexto fantasioso en el que deben imaginar una determinada situación de vida, caracterizar sus personajes, visualizarlos, así como sus requerimientos y características y con base en ello diseñar determinados objetos.

Un tercer ejemplo es el de Hammer y Reymen (2004) de la Eidhoven University of Technology en Holanda, ellos hablan de la relevancia de llevar a cabo la que denominan reflexión en el proceso de diseño. De acuerdo con ellos realizar dicha reflexión conduce a mejorar tanto el proceso de diseño como el producto que esta siendo diseñado, ya que se trata de un proceso que no sólo es racional sino sobre todo emocional. Los autores consideran por lo tanto a la dimensión emocional al mismo nivel de importancia que la racional. Consideran que ambas dimensiones juegan un rol específico en el proceso de diseño. Para incluir las emociones del diseñador de manera explícita en la reflexión del proceso de diseño, los autores identifican cinco pasos específicos para que sea llevada a cabo, en uno de ellos se refieren a la construcción de diversas imágenes vívidas por parte del diseñador. El siguiente se refiere a que el diseñador investigue profundamente el significado de dichas imágenes vividas y de este modo responda a cuestionamientos relevantes que atañen al proyecto.

En la búsqueda por definir un proceso para la proyección del diseño emocional (es decir desarrollar productos de diseño que conduzcan a vivir determinadas emociones): una de las dificultades con la que se han topado investigadores, proyectistas y ahora los docentes, es principalmente comprender cómo percibimos y vivimos las emociones a través del diseño, lo que ocasiona que desarrollar elementos de diseño desde la perspectiva emocional se torne difícil.

Actualmente con base en numerosos trabajos publicados en revistas y documentos generados como resultado principalmente de eventos académicos internacionales, surge la inquietud por la búsqueda de investigadores y proyectistas interesados en el tema diseño y emociones que aborden los siguientes tópicos:

- Identificar emociones del usuario generadas por el diseño

- Entender emociones del usuario producidas por el diseño

- Generar emociones en el usuario a través del diseño

Así desde nuestra perspectiva, la del docente, esta problemática nos planteó el reto de introducir al alumno al tema diseño y emociones mediante un concepto de enseñanza para el alumno de nivel superior que lo llevara a lograr un aprendizaje al mismo tiempo que estimulara su creatividad y principalmente le permitiera desarrollar la capacidad de proyectar la complejidad emocional a través de entender el impacto que tienen las emociones en el individuo. Dicho proceso de entendimiento se determinó que partiera de él mismo, de su propio universo emocional como un individuo. 


\section{Sobre la construcción de imágenes desde la emoción}

De acuerdo con la naturaleza de las emociones, la imagen permite aproximarse a éstas de la mejor y más originaria forma en que dichas emociones se manifiestan. Y se dice que la imagen permite una aproximación originaria a la emoción debido a que no es posible dar razones sobre ella, tan solo, como el propio Le Corbusier (2006) lo propone en El poema del ángulo recto, trazar las morfologías de sus manifestaciones, las geografías de los rastros que dejan al ocurrir y no exclusivamente las gráficas que genera un estudio cuantitativo de pulsiones neuronales en que fisiológicamente se manifiesta una "emoción".

La Dra. Alba (2010) en su publicación sobre las Intersecciones en la creación arquitectónica, para subrayar el hecho de que la forma más coherente de referir los afectos y emociones son las imágenes, comenta que

Nuestro entendimiento de la arquitectura reside en nosotros mismos, en nuestra biografía. Llevamos en nuestro interior imágenes que a lo largo de nuestra vida nos han ido configurando, muchas de ellas tiene que ver con vivencias y experiencias personales, otras están relacionadas con el campo de la arquitectura o con disciplinas artísticas afines (Alba, 2010),

ya que no se trata de representar emociones sino de evocarlas, de traerlas de nuevo a la presencia como si de volverlas a vivir se tratara.

La imagen, al igual que la emoción, es múltiple en su significado, amplia en las sugerencias que susurra, centrífuga en las posibilidades que desata tras haberla presenciado, debido a que ninguna de las dos, imagen y emoción, pueden manifestarse en una sola dirección o bien ser auto referenciales, ya que hay tantas lecturas de una imagen como emociones sentidas por individuos.

Es posible hablar de una misma imagen pero no decir lo mismo sobre ella. Se puede referir una misma emoción y ser diferente en circunstancias ocurridas como en la trascendencia para quien la experimentó.

Imagen y emoción son tan precisas como ambiguas, tan claras como oscuras, tan expresivas como mudas, entre otras razones porque a ambas no se les puede asir con taxonomías, aunque si situarse en ellas a través de bordes que señalan donde inician pero no donde terminan. Tan contradictoria es esta descripción como el señalar lo contrario, es decir, que a las emociones no es posible visualizarlas en estricto sentido tal y como se señalará más adelante en el Caso de estudio, sino que en las emociones sencillamente se está, parafraseando a Ortega y Gasset (2001) aunque respecto de las creencias, por lo que lejos de resultar complicado visualizar una emoción es prácticamente imposible. Una emoción, como ya se ha expuesto, puede ser pensada como la resultante de experimentar una situación determinada, por lo que no debiera parecer extraño concebirlas como un estado en el que se entra, que no como algo concreto y que pueda visualizarse.

Sin embargo la emoción, es algo factible de ser representado aunque no es contradicción sino la paradoja en la que, como afirma Venturi (1992) en su libro Complejidad y contradicción en la arquitectura, se significa el quehacer de esta actividad y lo que comparte con el diseño en tanto que forma de pensar el mundo. 
Estamos disciplinados en la tradición de esto o lo otro y carecemos de la agilidad mental -por no decir de la madurez de actitud- que nos permitiría los fragmentos y los detalles más sutiles considerados por la tradición de lo uno y lo otro [...] Si la fuente del fenómeno lo uno y lo otro es la contradicción, la percepción simultánea de un gran número de niveles provoca conflictos y dudas al observador y hace la percepción más viva (Venturi, 1992).

El diseño, al igual que la arquitectura, parte de supuestos que en realidad han de considerarse concretados paradójicamente para poder especificarlos, entre otras razones porque solo son supuestos. Y la imagen posibilita una situación como esta que, dentro de toda lógica, se antoja absurda por las razones antes referidas y bajo esta consideración, más que de concebir imágenes se trata de proponer 'imaginarios'.

Apoyados en este mismo sufijo, -ario, el bestiario, el ideario, el diario y hasta el diccionario se manifiestan, al igual que un imaginario, como el acto de compendiar ya relatos o imágenes sobre animales, ya ideas de autores, ya sucesos ordenados cronológicamente, ya voces de lenguas o ciencias de manera ordenada, con lo que se intenta dibujar un ámbito en el que representar para sí sus ideales, es decir de aquello que no existe sino en el pensamiento, según refiere el propio diccionario de la lengua española sobre el imaginario.

Pero en el caso del imaginario, y en especial como se propone dentro estas reflexiones, para el diseñador lo que se compendia no existe solo en la mente a caso porque, como lo explican las ciencias cognitivas, lo que en la mente ocurre es factible de ser representado como una serie de procesos lógicos, mientras que la emoción se derrama hacia dentro y fuera de quien se emociona, en direcciones múltiples y azarosas, originadas no necesariamente en el sujeto pero tampoco en aquello de lo que es objeto la emoción, de ahí que vaya y venga, que tan solo pueda ser representada como un ámbito, como un ánimo, como algo que no puede suponerse en la mente y en cambio si como el humor donde se encuentra situado el diseñador. Imaginar permite entonces, entre otras particularidades, situarse en la mirada que visualiza la imagen y no solo mirar. Descansa en medio exactamente de lo que sucede, tanto de lo que ocurre como el acto mismo de observar lo que acontece. En realidad nada ocurre fuera de quien imagina aunque tampoco dentro, como lo sugiere Sloterdijk (2010) en su escrito Tiempo de globo. Tiempo de mundo, debido a que es precisamente la mirada, que no los ojos, la que da sentido y significado al mundo, a lo que sucede.

Cuando el pensamiento moderno, remitido al lugar espacial, domina la situación, los seres humanos ya no pueden permanecer -como si estuvieran en casa- en sus tradicionales espacios interiores de mundo y en sus fantasmáticas dilataciones y redondeos. [...] han dejado sus casas lingüísticas locales y sus tiendas celestes, montadas y asentadas terrenamente, para moverse ya para siempre en un exterior insuperable que les precedía aunque también en un exterior cada día más organizado, en el que convergen la política social y la arquitectura de interiores (Sloterdijk, 2010). 
Imaginar, así como asistir a imaginarios, no es una práctica arbitraria que parte del desorden al que siempre se han asociado éstas. La imaginación, y el compendio de sus productos, en ocasiones se relacionan a desórdenes tan severos como la locura, en gran medida por lo que de irreales tienen. Sin embargo la imaginación, y todavía más, el imaginario que se nombra así por las imágenes que compendia, solo ocurre por la organización de elementos afectivos y emocionales que la conforman aunque no de forma secuencial o lineal sino, como lo señala Sloterdijk (2010), bajo cierto "espacio de representación homogéneo y dividido arbitrariamente", en el que ahora auténticamente "habitamos" por los escenarios que desatan.

Algo como esto puede ser referido a las reflexiones que, en torno a las tecnologías de la información, de Kerckhove puntualiza (1999).

[...] la RV (Realidad Virtual) se convierte en una extensión tecnológica directa y también en una expresión de los procesos mentales que se desarrollan en el diseño. Las imágenes mentales se dotan de formas gráficas que se pueden cambiar por voluntad, de forma muy parecida a como las cosas ocurren en nuestra propia mente. [...] con ellos somos capaces de internarnos realmente en los contenidos de nuestra mente ampliada (Kerckhove, 1999).

Mente que si se amplía no es solo porque ella misa expande sus posibilidades de procesamiento sino que auténticamente, y dadas las características de las TIC según lo referido por de Kerckhove (1999), es posible presenciar lo que se piensa delante de los propios ojos. No es entonces solo un asunto de procesos funcionales mentales, aclara este autor más adelante, entre otras razones porque, como ya se ha señalado anteriormente, las imágenes mentales son las huellas de afectos y emociones, y en ese sentido, atendiendo a lo antes referido, son el imaginario que nos configura, que nos imagina.

Las imágenes, en especial aquellas sobre nosotros mismos, las que hemos emocional y afectivamente presenciado, pasan delante de mí sin que esto sea solo una metáfora y el ejemplo de las TIC dan testimonio de ello. Mis imágenes, lo son porque son el yo representado, acaso es por ello que me emocionan.

Quién no ha llorado delante alguna escena cinematográfica que, ingenuidad y puerilidad aparte de los elementos que en ocasionas acompañan al clímax de una trama, conmueve hasta las lágrimas mas por lo que dicha imagen me recuerda a mí que por emotiva en sí. La escena o la imagen emotiva conmueven no porque ello sea propio de dicha escena o imagen como se ha venido señalando, sino porque es el acto mismo de visualizar la mirada que mira. En donde el acento no se encuentra en el recuerdo, en la memoria que se guarda de lo ocurrido sino en la capacidad que tengo de reconocerme emocional y emotivamente delante de tales imágenes; más que recordar, reconozco.

La imagen y su sentido emocional, que no su carga emocional, son los recuerdos que permiten identificarme, es la repetición de mi en un afán por saberme y de nuevo, no en el sentido de conocerme, sino de reconocerme. Bajo esta consideración, visualizar imágenes emocionadas es repetir en términos de Kierkegaard (2009), en tanto que son presencia expectante y protagonizante: 
[...] la repetición viene a expresar de un modo decisivo lo que la reminiscencia representaba para los griegos. De la misma manera que éstos enseñaban que todo conocimiento era una reminiscencia, así enseñará también la nueva filosofía que toda la vida es una repetición (Kierkegaard, 2009).

Conocer es en realidad conocerse mediante la repetición que permiten las imágenes, porque la repetición no es un acto mecánico o mecanicista de quien lo comete, es la propia percepción, la percepción de sí y por sí, la percepción de Merleau-Ponty (1985) que condiciona la posibilidad de percibir solo aquello que fuera una experiencia previa.

Sin embargo, repetir no es recordar aclara Kierkegaard debido a que la auténtica repetición, suponiendo que sea posible, hace al hombre feliz, mientras que el recuerdo lo hace desgraciado, en gran medida por lo caduco de su significado ya que el recuerdo conserva su condición de pasado, de ido mientras que la repetición se mantiene vigente por lo que de imagen tiene.

El ánimo metafórico que implica la visualización de algo que se presupone concretado, tal como se señalaba al inicio de estos señalamientos, revela por un lado una cualidad propia de todo diseñador: la capacidad de situarse en el centro mismo de la imagen que concibe, lo que no es igual a preconcebir o prefigurar, entre otras razones porque es la propia emoción quien da lugar a la imagen, aquella que es visualizada y al mismo tiempo por la que puede decirse uno emocionado.

Y esta es la razón por la que imaginar lo concretado para así concretar, es factible de ocurrir debido a que es la emoción quien imaginando sitúa y acaso encarna el sentido que tiene la experiencia. Pero de igual modo, el deseo por concretar imágenes en las que representar una idea, ciertas intuiciones sobre lo que emocionalmente solo podría representarse de esa manera: imaginariamente, es decir, mediante imágenes.

\section{Caso de Estudio. La experiencia emotiva como instrumento cognitivo}

De las Unidades de Enseñanza Aprendizaje (UEA) o materias que conforman el plan de estudios de la licenciatura en Diseño de la UAM Cuajimalpa, la materia en la cual se llevó a cabo esta experiencia fue la denominada "laboratorio de diseño integral" perteneciente al segundo año (de un total de cuatro) de la carrera de diseño.

Las materias del tipo laboratorio del plan de estudios de dicha licenciatura contemplan sobre todo la experimentación en torno al desarrollo de proyectos. El laboratorio ya mencionado, principalmente tiene como objetivo general la proyección de la dimensión expresiva - comunicativa del diseño.

Así, en este curso, a manera de introducción para el alumno se le proporcionaron como primer paso 4 lecturas para introducirlo al tema diseño y emociones, que fueron las siguientes:

1. Norman (2004) sobre las temáticas: emociones y percepción del diseño.

2. Jordan (2002) sobre las temáticas: diseño de productos agradables, los cuatro placeres, y comprensión de la experiencia humana. 
3. Schifferstein (2008) sobre las temáticas: experiencia de producto, sentidos, significados, y valores.

4. Bedolla (2012), sobre las temáticas: diseño multisensorial, diseñar sensaciones, emociones, y experiencias integrales sensorialmente.

Se plantearon preguntas para trabajar o analizar los textos en clase ya que, el planteamiento de preguntas, guía la discusión hacia lo importante a destacar en los textos, cosa que difícilmente sucedería si se dejara sin alguna guía específica la discusión.

Por otra parte, una segunda ventaja del planteamiento de preguntas es que de este modo los estudiantes se ven mas comprometidos a leer los textos para poder reflexionar en clase sobre ellos. Este es el método que sugiere la Action Research Methodology (Bassey 1998) en la que representa una herramienta que se inserta en el trabajo cotidiano de clase y permite, partiendo de formular preguntas relevantes, conducir el desarrollo del proceso de enseñanza aprendizaje.

De esta manera se plantearon distintas preguntas con base en tres ideas para la reflexión de los textos:

a) Importancia de considerar la dimensión emocional para el proyectista, y para los usuarios.

b) Capacidad del diseño de satisfacer necesidades emocionales de las personas o usuarios.

c) Identificar y describir la naturaleza de las experiencias de usuarios a través de los productos del diseño.

\section{Estructura del curso}

Para conducir al alumno a conocer el impacto que tienen las emociones generadas por el diseño en el usuario, se consideró desde un inicio un aspecto que permitió definir el modo de trabajo que conduciría el curso y por supuesto las actividades a seguir.

Dicho aspecto se refiere a tener en cuenta la naturaleza humana caracterizada con base en lo que señala Goleman (1995)

tenemos dos mentes, una que piensa y otra que siente, el pensamiento es un proceso con muchas caras. Las emociones son una de las facetas de ese proceso, una parte tan integral del mismo como el pensamiento lógico, lineal y verbal del hemisferio izquierdo. De la misma manera que no pensamos sólo con un único hemisferio, sino que los dos son necesarios, tampoco nos limitamos a procesar la información, además la sentimos (Goleman, 1995).

De acuerdo con lo anterior fue necesario hacer conscientes a los alumnos y conducirles a que se concentraran en la mente "que siente". De este modo el curso se estructuró a lo largo de una serie de ejercicios que les permitieron:

a) Evocar y reflexionar personalmente en torno a la experiencia emocional que cada uno de ellos ha vivido en la interacción con productos del diseño (objetos, espacios, etc.) de 
su cotidianidad, de manera que los llevara a través de imágenes mentales y personales a la remembranza, visualización, identificación, y finalmente comprensión del ámbito emocional humano en relación a productos del diseño con los que interaccionan cotidianamente, que les condujera a darse cuenta de la existencia de este "lazo" del ser humano con el mundo artificial.

b) Identificar, explorar y manejar la dimensión expresiva del producto mediante la identificación y exploración de los elementos plásticos o expresivos que integran o pueden integrar el lenguaje del diseño que les permitieran proyectar elementos de diseño desde la dimensión emocional humana, es decir llegar a "diseñar emociones".

Evocar y reflexionar personalmente en torno a la experiencia emocional ha representado un aspecto central para el desarrollo del curso ya que experimentar, vivir una experiencia, es lo que permite a todo individuo conformar conocimiento gracias a la transmisión y procesamiento de información a través de ella. Este concepto supone una idea de la percepción más amplia de la mantenida tradicionalmente, ya que las distintas dimensiones humanas (tanto de naturaleza racional como irracional) contribuyen de forma valiosa a la construcción de la experiencia global.

Para lograr construir experiencias a través de interacciones emocionalmente ricas con los productos del diseño, los diseñadores necesitamos métodos o modos de sondear el mundo experiencial de las personas, motivo por el que este curso fue ocasión de experimentar enfoques o acercamientos frescos para alcanzar dicho objetivo.

\section{Actividades específicas del curso}

Después de las lecturas de introducción al curso, la primera actividad fue conducir al alumno a hacer un fuerte hincapié en la evocación y narración de la vivencia de su experiencia emocional personal. Se les condujo a conocer el mundo experiencial emotivo de las personas iniciando con el suyo propio; el ejercicio se trató entonces de la evocación de experiencias que a nivel personal les fueran emocionalmente significativas.

Para ello se les pidió la creación de una narración, expresando las emociones que vivían al interaccionar o hacer uso de uno o más productos de su propio entorno cotidiano. El objetivo fue que experimentaran personalmente y reflexionaran en torno a las experiencias emocionales que cada uno de ellos vivía en la interacción con determinados objetos de manera que los llevara a la visualización, identificación, reflexión y finalmente comprensión del ámbito emocional humano.

Posteriormente se les condujo a la realización del análisis grupal de dichas narraciones, lo que llevó al grupo a la identificación de diferentes "niveles de placer" de las personas o usuarios y al mismo tiempo les llevó a visualizar claramente el papel central del conjunto de sentidos humanos en la conformación de experiencias con productos del diseño cotidianos, de esta manera se buscó que comprendieran la relevancia de desarrollar productos de diseño con base en los procesos sensoriales humanos. 
La segunda actividad que los alumnos llevaron a cabo fue observar a diferentes usuarios vivir experiencias con productos del diseño en diferentes contextos, e inclusive tratar de ser empáticos con ellos, visualizándose ellos mismos en los mismos contextos y situaciones. En relación a estas observaciones los alumnos tuvieron la posibilidad de registrarlas audiovisualmente, de esta manera tuvieron la posibilidad de analizar las situaciones según les fuera necesario. Esta segunda manera de acercarse a las emociones generadas a través de productos del diseño fue otra dimensión de la visualización y vivencia de experiencias para el alumno.

De esta manera re-vivir y observar experiencias emotivas le otorgó al alumno la oportunidad de ser empático, visualizar la relevancia y naturaleza de las emociones en las personas con el fin de finalmente lograr la integración de experiencias significativas para las personas a través de productos del diseño.

La siguiente actividad consistió en identificar y explorar los atributos visuales, auditivos, táctiles, y olfativos que integran o pueden integrar el lenguaje del diseño. Se trató de un trabajo de exploración y reflexión colectiva con el fin de conducirlos a identificar y explorar sus características y posibilidades principalmente expresivas en relación a la dimensión emocional humana.

Los alumnos por lo tanto llevaron a cabo dicha identificación y exploración, con base en la búsqueda y presentación por parte de cada uno de ellos de:

1. Imágenes (de elementos digitales, objetos diversos, y espacios) para conducirlos a que identificaran los distintos atributos visuales del lenguaje del diseño, es decir: forma, color, y gráficos decorativos.

2. Cosas materiales (de distintos materiales como plástico, tela, cartón, cerámica, vidrio, metal, etc.) para conducirlos a que identificaran los diferentes atributos táctiles que tiene o puede tener el lenguaje del diseño es decir: texturas táctiles, movimiento, temperatura y presión.

3. Cosas materiales que los condujeran a identificar los diferentes atributos auditivos del lenguaje del diseño en objetos es decir: música, sonidos, ruido. Algunos de los objetos presentados fueron por ejemplo un teléfono celular, despertador, juguetes diversos, un mouse (hardware), etc.

4. Elementos digitales que los condujeran a identificar atributos auditivos en ellos distintos de los anteriores es decir: música, sonidos, e inclusive ruido que caracterizan a los elementos digitales

5. Cosas materiales que contaran con textiles en contacto con el cuerpo humano de alguna manera, o bien que tuvieran plásticos en contacto con alimentos frescos o descomposición, con el fin de conducirlos a que identificaran atributos olfativos en ellos a través de la emisión de aromas, o bien de la absorción de olores.

Es relevante mencionar que a través de esta actividad exploratoria los estudiantes identificaron no solo los aspectos directamente en relación con la dimensión emocional del lenguaje del diseño, sino también en muchos momentos con la funcional, ya que se dieron cuenta de la utilidad de determinados atributos sensoriales (distintos de los visuales) en el funcionamiento de distintos productos del diseño. 
Así, se condujo al alumno a la identificación y exploración colectiva de los elementos del lenguaje del diseño que representan los componentes del "alfabeto" que les permitirían posteriormente "escribir emociones" al diseñar.

La siguiente actividad del curso, se trató ya de un proceso aplicativo de todo lo explorado y comprendido en relación a la construcción de experiencias, con base en la aplicación de los atributos sensoriales del diseño explorados que pueden integrar el "alfabeto" para diseñar emociones. Un primer ejercicio aplicativo consistió en la elección por parte del alumno de una forma ancestral o legendaria ya identificada y proponer algún elemento de diseño que aprovechara su significación. Se les pidió que desarrollaran un objeto especifico que en ese caso podría ser o bien un despertador o una silla, aplicando las cualidades de la forma para caracterizarlo y comunicar emociones especificas.

Una actividad más del curso perteneciente al proceso aplicativo de los atributos sensoriales del diseño que pueden integrar el "alfabeto" para diseñar emociones, consistió en que manejaran los efectos y características emocionales de los colores y los relacionaran con otros atributos sensoriales integrándolos congruentemente. Este ejercicio tuvo el objetivo adicional de conducir a los estudiantes a entender y aprovechar las sinestesias (asociación de sensaciones) del conjunto de atributos sensoriales con el color. Con base en esto se les pidió entonces que integraran digitalmente diversidad de imágenes en un breve video.

\section{Actividades Finales}

Dos actividades integraron la parte final del curso:

a) La primera actividad final consistió en un ejercicio cuyo objetivo fue que integraran los efectos emocionales de los atributos sensoriales siguientes: textura, forma, y color. En esta actividad los estudiantes trabajaron en equipos sobre 2 distintos productos del diseño: 1 sillón y 1 folleto. Desarrollaron modelos de cada uno de ellos.

Dado que el objetivo fue que buscaran reflejar diferentes necesidades y expresiones humanas, a cada equipo se le asignó una de las siguientes expresiones que pueden tener distintos productos del diseño y que están directamente relacionados con emociones y sensaciones humanas:

Expresar descanso-comodidad

¿Qué textura, forma, color, temperatura, comunican visual y táctil en un sillón descanso y comodidad? Y ¿Qué textura, forma, color, temperatura, comunican visual y táctil en un folleto descanso y comodidad?

Expresar frescura

¿Qué textura, forma, color, temperatura, comunican visual y táctil en un sillón frescura? Y ¿Qué textura, forma, color, temperatura, comunican visual y táctil en un folleto frescura?

Expresar diversión

¿Qué textura, forma, color, temperatura, comunican visual y táctil en un sillón diversión? Y ¿Qué textura, forma, color, temperatura, comunican visual y táctil en un folleto diversión? 
Expresar ansiedad -estrés

¿Qué textura, forma, color, temperatura, comunican visual y táctil en un sillón ansiedadestrés? Y ¿Qué textura, forma, color, temperatura, comunican visual y táctil en un folleto descanso y comodidad?.

Expresar riqueza-lujo

¿Qué textura, forma, color, temperatura, comunican visual y táctil en un sillón riquezalujo? Y ¿Qué textura, forma, color, temperatura, comunican visual y táctil en un folleto riqueza lujo?

b) La segunda actividad consistió en identificar e integrar efectos y congruencias emocionales entre: olor, forma y color, desarrollando los siguientes ejercicios; se les asignó solo uno por equipo de trabajo.

Se les sugirió que el olor se representara o trabajara a través de lo que visualmente el objeto de diseño expresara. Cómo es el olor del producto y de qué manera la forma y la textura permitían percibir el olor del producto que el objeto tenía. Los problemas específicos fueron:

Vaso para café; preguntas guía planteadas para su desarrollo: ¿Cómo es el olor del café? ¿Qué textura, forma, colores lo representan?

Botella de perfume; preguntas guía planteadas para su desarrollo: ¿Cómo es el olor del perfume que contiene? ¿Qué textura, forma, colores lo representan?

Contenedor de detergente/suavizante líquido; preguntas guía planteadas para su desarrollo: ¿Cómo es el olor del detergente/suavizante? ¿Qué textura, forma, colores lo representan?

Contenedor de shampoo, preguntas guía planteadas para su desarrollo: ¿Cómo es el olor del shampoo? ¿Qué textura, forma, colores lo representan?

Contenedor de galletas; preguntas guía planteadas para su desarrollo: ¿Cómo es el olor de las galletas? ¿Qué textura, forma, colores lo representan?

\section{Comentarios Finales}

Después de esta experiencia, puede decirse que en general hubo gran interés y participación en el tema y en la realización de los ejercicios que estructuraron el curso sin embargo, para un mejor aprovechamiento del estudiante, es conveniente y necesario, que en materias anteriores a este curso, dentro del plan de estudios, se introduzca al alumno a una perspectiva multisensorial desde donde estudiar y entender al usuario; y que inicie de alguna manera la consideración de la dimensión afectiva emocional humana.

Igualmente es sumamente necesario que se introduzca previamente al alumno a la consideración y manejo amplio del lenguaje expresivo del diseño que no se limite (y los límites) al estudio y uso de los atributos visuales (forma, color, gráficos) sino al resto de ellos 
(táctiles, auditivos, y olfativos) para que realmente puedan empezar a conceptualizar experiencias de diseño mediante objetos, elementos digitales, o espacios que les permitan la proyección de productos placenteros y memorables para el usuario mediante la multisensorialidad.

En relación a la imagen como instrumento cognitivos es relevante mencionar que las imágenes en el diseño de siempre han sido objeto o bien de diseño mismo, como en el caso del diseño gráfico, o bien como instrumento para poder pensar las propuestas de diseño en las distintas manifestaciones que hasta ahora se han concretado: gráficas, de objetos o de espacios.

En ese sentido, parecería que poco o nada aportan estas reflexiones, si se aborda el tema de las imágenes bajo estas consideraciones, sin embargo, lo que en realidad nombra el calificativo de emocionales que se asocia a dichas imágenes, es mucho más que un adjetivo ya que en realidad señala en dirección de la experiencia que se pretende evoque, tenga no solo el alumno al momento de concebir su propuesta de diseño sino sobre todo la que el destinatario tendrá de dicha propuesta.

\section{Bibliografía}

Alba Dorado, M. I. (2010). Intersecciones en la creación arquitectónica, Universidad de Sevilla. Bassey, M. (1998). Action Research for improving educational practice, en Halsall, R. (ed) Teacher research and school Improvement: Opening Doors from inside, Open University Press. Bedolla Pereda, D. (2012). Diseño Multisensorial, diseño centrado en los sentidos. Leipzig: Editorial Académica Española.

(2009). Hacia la satisfacción del ámbito afectivo humano, nuevas tendencias del diseño. Diseño y Sociedad num. 27, segundo semestre de 2009 Revista de la Universidad Autónoma Metropolitana Xochimilco. Disponible en: http://disenoysociedad.xoc.uam.mx/

Cañada J. (2005). Donald Norman y el diseño emocional, en: Arce Asociación de Revistas Culturales de España, num. 113 marzo de 2005. Disponible en: www.revistasculturales. com/articulos/65/visual/317/1/donald-norman-y-el-diseno-emocional.html

Denton H., McDonagh D., Baker S., Wormald P. (2004). Introducing the student designer to the role of emotion in design, in McDonagh D., Hekkert P., Van Erp J., Gyi D., Design and Emotion The experience of everyday things. London: Taylor and Francis.

Desmet, P. M., Hekkert P. P. (2009). Special Issue Editorial: Design and Emotion, in International Journal of Design. Special Issue in Desig \& Emotion, Vol 3 num 2.

(1998). The basis of product emotion, in Green William, S., and Jordan Patrick W. (ed). Pleasure with products. London and New York: Taylor \& Francis.

Gobé, M. (2005). Branding emocional, el nuevo paradigma para conectar las marcas emocionalmente con las personas. Barcelona: Divine Egg publicaciones.

Goleman, D. (1995). Emotional intelligence. New York: Bantam Books.

Hammer, D., Reymen, I. (2004). The role of emotion in design reflection, in McDonagh D., Hekkert P., Van Erp J., Gyi D., Design and Emotion. The experience of everyday things. London: Taylor and Francis. 
Helander, M. G., Khalid, H. M. (2006). Affective and pleasurable design, in Salvendy, G. (ed). Handbook on Human Factors and Ergonomics. New York: Wiley.

Jordan Patrick, W. (2002). Designing pleasurable products, an introduction of the human factors. London: Taylor \& Francis Group.

Kerckhove, D. (1999). La piel de la cultura. Barcelona: Gedisa.

Khalid, H. M., Helander, M. G. (2004). A framework for affective customer needs in product design. Theor. Issues Ergon. Sci. 5 (1).

Kierkegaard, S. (2009). La repetición. Madrid: Alianza ed.

Koninklijke. (2006). Philips Electronics N.V. July, Netherlands. Disponible en: www.illumi nazione.philips.it/es_es/project/downloads/121101_c1_opm_es_catherina.pdf.

Le Corbusier (2006). Le poeme de l'angle droit. Madrid: Exposiciones ed.

Merleau-Ponty M. (1985). Fenomenología de la percepción. Barcelona: Planeta - Agostini.

Norman D. (2004). Emotional design, why we love or hate everyday things. New York: Basic Books.

Ortega y Gasset (2001). Ideas, creencias y otros ensayos de filosofía. Madrid: Alianza ed.

Schifferstein Hendrik N. J., Hekkert, P. (Eds.) (2008). Product Experience. Oxford: UK: Elseiver.

Sloterdijk, P. (2010). En el mundo interior del capital. Madrid: Siruela.

Venturi, R. (1992). Complejidad y contradicción en la arquitectura. Barcelona: Gustavo Gili.

Resumo: Um modo de abordar o ensino do design desde a criatividade e sua conseqüência, a inovação, é propiciando nos alunos a vivência de experiências sensoriais e emotivas. A detecção e caracterização de problemáticas a resolver por meio do design, desde a perspectiva deste tipo de experiências, conduzem aos alunos a construir imagens mais precisas para dar resposta afetivo-significativas durante o processo de design.

Palavras chave: criatividade - Design - experiências emotivas - experiências sensoriais inovação.

Summary: One approach to design education from the creativity and therefore innovation is fostering in students the experience of sensory and emotional experiences. The detection and characterization of problems to be solved by designing from the perspective of such experience leads students to build more accurate "images" for significant affective answers during the design process.

Keywords: creativity - Design - emotional experiences - innovation - sensory experience. 